\title{
Easily Attainable Phenothiazine-Based Polymers for Polymer Solar Cells: Advantage of Insertion of S,S-dioxides into its Polymer for Inverted Structure Solar Cells
}

\author{
Gyoungsik Kim, ${ }^{\dagger}$ Hye Rim Yeom, ${ }^{\dagger}$ Shinuk Cho, ${ }^{\ddagger}$ Jung Hwa Seo, ${ }^{\S}$ Jin Young Kim, ${ }^{\dagger}$ and Changduk Yang ${ }^{*}{ }^{\dagger}$ \\ ${ }^{\dagger}$ Interdisciplinary School of Green Energy and KIER-UNIST Advanced Center for Energy, Low Dimensional Carbon Materials \\ Center, Ulsan National Institute of Science and Technology (UNIST), Ulsan 689-798, South Korea \\ ${ }^{\ddagger}$ Department of Physics and EHSRC, University of Ulsan, Ulsan 680-749, South Korea \\ ${ }^{\S}$ Department of Materials Physics, Dong-A University, Busan 604-714, South Korea
}

Supporting Information

\begin{abstract}
Two donor- (D-) acceptor (A) type polymers based on a soluble chromophore of phenothiazine (PT) unit that is a tricyclic nitrogen-sulfur heterocycle, have been synthesized by introducing an electron-deficient benzothiadiazole (BT) building block copolymerized with either PT or phenothiazine-S,S-dioxide (PT-SS) unit as an oxidized form of PT. The resulting polymers, PPTDTBT and PPTDTBT-SS are fully characterized by UV-vis absorption, electrochemical cyclic voltammetry, Xray diffraction (XRD), and DFT theoretical calculations. We find that the maximum absorption of PPTDTBT is not only markedly red-shifted with respect to that of PPTDTBT-SS but also its band gap as well as molecular energy levels are readily tuned by the insertion of $S, S$-dioxides into the polymer. The main interest is focused on the electronic applications of the two polymers in organic field-effect transistors (OFETs) as well as conventional and inverted polymeric solar cells (PSCs). PPTDTBT is a typical p-type polymer semiconductor for OFETs and conventional PSCs based on this polymer and PC ${ }_{71} \mathrm{BM}$ show a power conversion efficiency (PCE) of $1.69 \%$. In case of PPTDTBT-SS, the devices characteristics result in: (i) 1 order of magnitude higher hole mobility $\left(\mu=6.9 \times 10^{-4} \mathrm{~cm}^{2} \mathrm{~V}^{-1} \mathrm{~s}^{-1}\right)$ than that obtained with PPTDTBT and (ii) improved performance of the inverted PSCs (1.22\%), compared to its conventional devices. Such positive features can be accounted for in terms of closer packing molecular characteristics owing either to the effects of dipolar intermolecular interactions orientated from the sulfonyl groups or the relatively high coplanarity of PPTDTBT-SS backbone.
\end{abstract}

\section{INTRODUCTION}

The dramatic growing need for renewable energy supply is increasing the demand for new technologies for photovoltaic energy conversion. Polymeric solar cells (PSCs) have attracted much attention due to their potentials for low cost, lightweight, and good compatibility with the roll-to-roll process for making flexible large area devices. ${ }^{1-5}$ So far, the most efficient polymer solar cell system is built on the concept of bulk-heterojunction $(\mathrm{BHJ})$ structure, which uses a blend of an electron-donor polymer and an electron-acceptor fullerene. ${ }^{3}$ Recently, power conversion efficiencies (PCEs) of $6-8 \%$ have been realized by using new conjugated polymer donors ${ }^{6-10}$ or novel fullerenederived acceptors. ${ }^{11-13}$

Aside from achieving higher PCEs, improving the stability of PSCs is equally important. In general, conventional PSCs are comprised of a $\mathrm{BHJ}$ active layer sandwiched between an acidic poly(3,4-ethylenedioxythiophene):poly(styrenesulfonate)- (PEDOT:PSS-) coated indium tin oxide (ITO) anode and a low work-function metal cathode (e.g., $\mathrm{Al}$ and $\mathrm{Ca}$ ). In such a device structure, not only does the cathodes easily oxidize in air but also the acidic PEDOT:PSS-ITO can suffer interfacial degradation over the operating lifetime. ${ }^{14}$ As alternative to the regular device configuration, PSCs with an inverted device structure have been developed, which enables the use of stable and printable high work-function metals (e.g., $\mathrm{Ag}$ and $\mathrm{Au}$ ) as hole collecting top electrodes and n-type low work-function metal oxides (e.g., $\mathrm{TiO}_{x}$ and $\mathrm{ZnO}$ ) as electron collecting bottom electrodes. ${ }^{15,16}$ Thus, with advances made on the aforementioned efficiency front, the lifetime and reliability of PSCs are also envisaged by utilizing the inverted PSC configuration through the replacement of the low workfunction metal cathode and the elimination of PEDOT:PSS layer.

Recently, several classes of narrow bandgap donor- (D-) acceptor (A) type polymers have been developed to better harvest the solar spectrum with deeper HOMO energies that can be helpful in realizing high open circuit voltage $\left(V_{\mathrm{OC}}\right)$ and PCEs, as the $V_{\mathrm{OC}}$ value of PSCs is directly proportional to the offset between the HOMO level of electron donor and the LUMO level of electron acceptor. ${ }^{5,17-19}$ Among them, poly(2,7-carbazole-alt-dithienylbenzothiadiazole) (PCDTBT) showed particularly interesting achievement of a PCE in excess of $6 \%$ from a $\mathrm{BHJ}$ cell with $V_{\mathrm{OC}}$ value approaching $0.9 \mathrm{~V}$ as well as remarkable stability at higher temperature for extended periods of time. ${ }^{17,20}$ More recently, efficient, air-stable inverted $\mathrm{BHJ}$ solar cells based on PCDTBT fabricated with a lowtemperature annealed sol-gel-derived $\mathrm{ZnO}$ film as an electron transport layer have also been demonstrated. ${ }^{15}$

Received: December 8, 2011

Revised: January 15, 2012

Published: February 3, 2012 


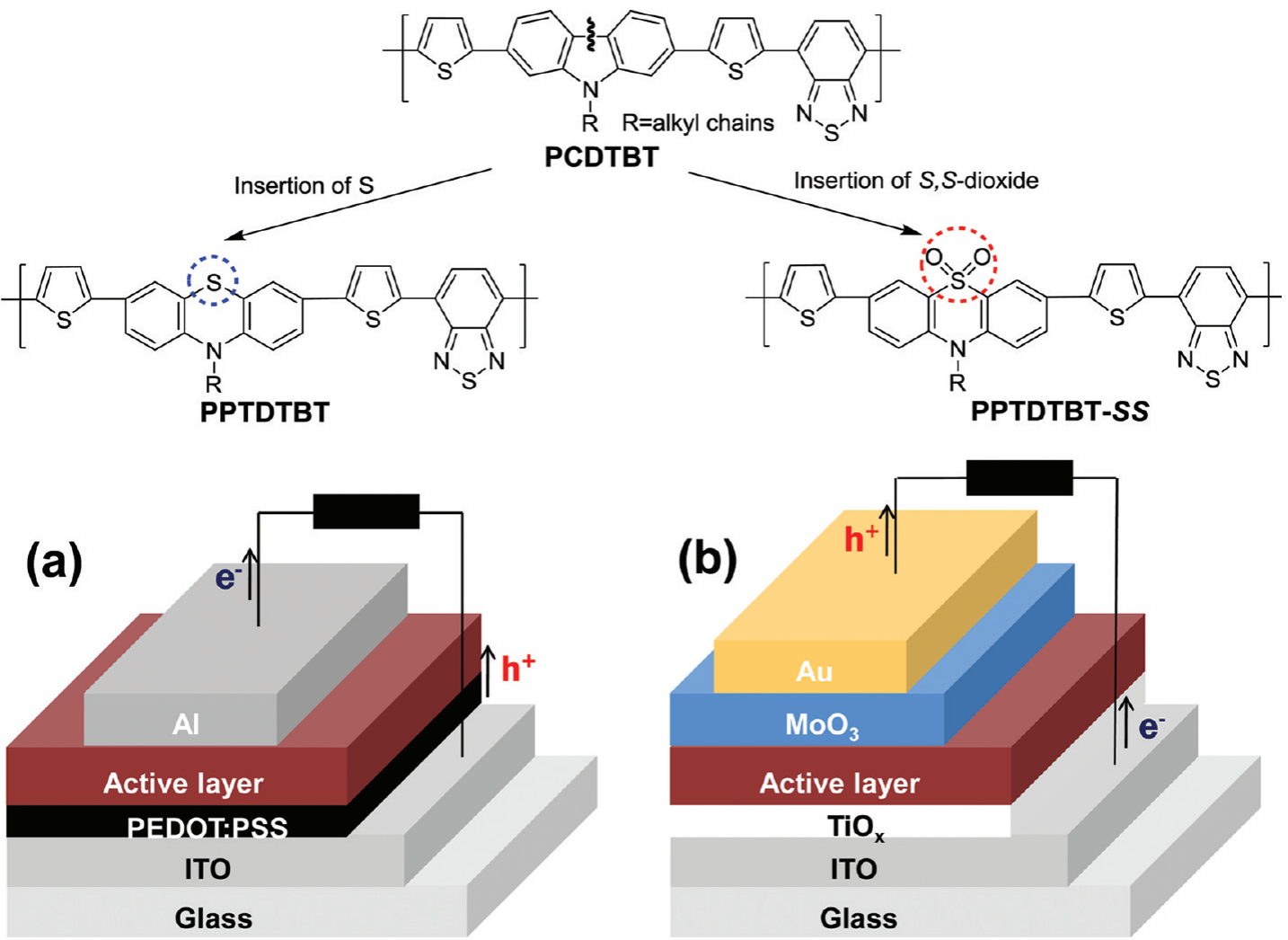

Figure 1. Molecular structures of PCDTBT and phenothiazine-based polymers. Schematic depiction of the conventional structure (a) and inverted structure (b) of the PSCs used by our research group.

However, to prepare the tricyclic 2,7-carbazole monomer, 4,4'-dibromobiphenyl must first undergo a nitration reaction followed by a Cadogan ring closure reaction. ${ }^{21}$ The relatively long synthetic routes will limit their future commercial application in PSCs. To realize potentially low manufacturing costs, it is critical to obtain readily synthesized polymers from commercial products.

In this regard, we focused our attention to the well-known phenothiazine building block, considering the following: (i) Heterocyclic phenothiazine unit is structurally similar to the carbazole moiety but it contains an additional sulfur atom. As a more powerful electron-rich molecule, the phenothiazine is better suited for the development of enhanced intramolecular charge transfer (ICT) polymers. In addition, its "butterfly" nonplanar structure impedes $\pi$-stacking aggregation and intermolecular excimer formation, resulting in diverse optoelectronic applications. ${ }^{22-26}$ (ii) Not only is phenothiazine cheap and commercially available but also it can be easily tailored by connecting solubilizing groups to the $\mathrm{N}$ atom to improve solubility. This is important since the barrier for preparation of materials in terms of a cost effectiveness must be overcome to realize the commercial potentials of PSCs. (iii) Following oxidation of phenothiazines to phenothiazine-S,Sdioxides, the electron-withdrawing sulfones would reduce the electron density in the polymer backbone, most likely rendering it more resistant toward the oxidation while simultaneously tuning the electronic properties. In particular, we hypothesized that the hydrophilicity of the $\mathrm{SO}_{2}$ groups can promote the compatibility and low contact resistance through the potential interaction with oxides in the inverted $\mathrm{BHJ}$ solar cells integrated with metal oxide materials as an electron transport and an hole transport between the ITO/BHJ and $\mathrm{BHJ} /$ metal interfaces.
Herein, we report two new polymers incorporating either phenothiazine or its oxidized analogue phenothiazine-S,Sdioxide as the donor and benzothiadiazole as the acceptor, namely poly $(N$-(2-decyltetradecyl)-3,7-phenothiazine-alt-5,5(4',7'-di-2-thienyl-2',1',3'-benzothiadiazole)) (PPTDTBT) and poly $(N$-(2-decyltetradecyl)-3,7-phenothiazine-S,S-dioxide-alt5,5-(4',7'-di-2-thienyl-2',1',3'-benzothiadiazole)) (PPTDTBT$S S$ ), respectively (Figure 1 ). These polymers are tested in both conventional and inverted solar cell devices using the fullerene derivative (see Figure $1 \mathrm{a}$ and $\mathrm{b}$ ). We find that PSCs based on PPTDTBT in a conventional architecture can reach PCE as high as $1.69 \%$, whereas the utilization of its oxidized form PPTDTBT-SS into inverted solar cells shows improved performance $(\mathrm{PCE}=1.22 \%)$, when compared to that of its conventional devices. The results obtained here are very helpful for molecular design strategies to obtain inverted solar cells with higher device performance.

\section{RESULTS AND DISCUSSION}

The synthetic routes to the intermediates and the polymers (PPTDTBT and PPTDTBT-SS) are outlined in Scheme 1. Synthesis of 4,7-dibromo-2,1,3-benzothiadiazole (1), 4,7-di-2thienyl-2,1,3-benzothiadiazole (2), and 4,7-bis(5-bromo-2thienyl)-2,1,3-benzothiadiazole (3) were prepared by following the literature procedures. $^{27}$ In order to guarantee good solubility of phenothiazine-based polymers, the bulky branched side chain (2-decyltetradecyl) was introduced onto the nitrogen atom on the phenothiazine unit. Dibromination of 4 by $N$ bromosuccinimide (NBS) in DMF afforded 3,7-dibromo- $\mathrm{N}$-(2decyltetradecyl)phenothiazine (5) in 93\% yield which was transformed into the corresponding diboronic ester 6 via lithiation and subsequent quenching with 2 -isopropoxy-4,4,5,5- 
Scheme 1. Synthesis of PPTDTBT and PPTDTBT-SS ${ }^{a}$



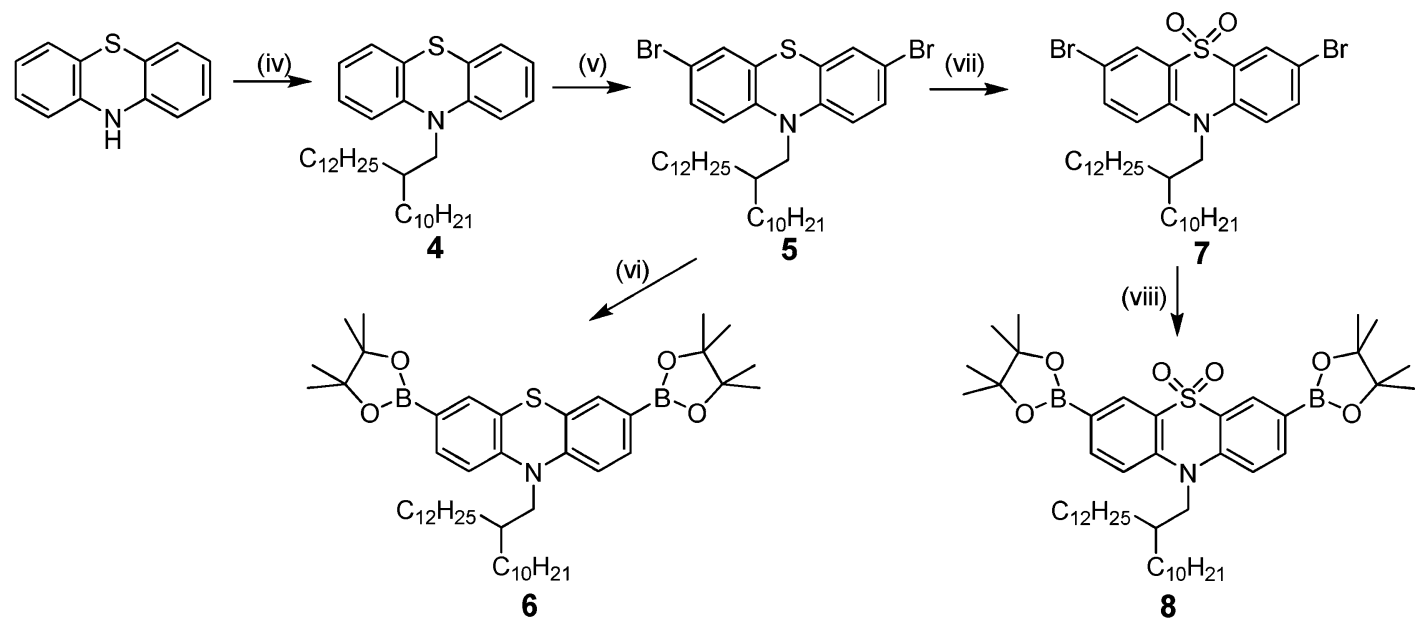

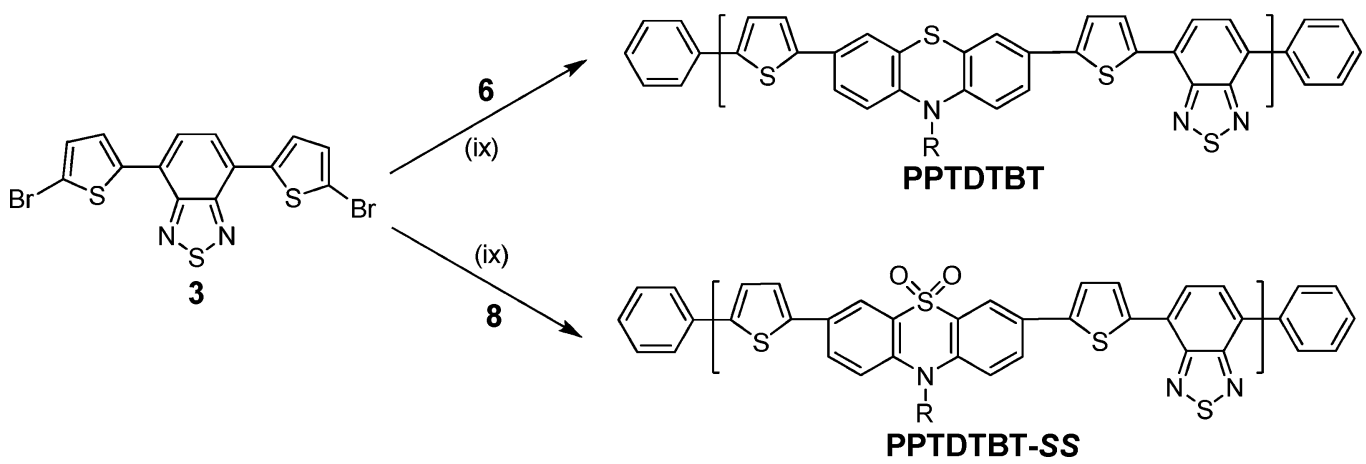

${ }^{a}$ Reagents and conditions: (i) $\mathrm{Br}_{2}, \mathrm{HBr}$, reflux; (ii) 2-(tributylstannyl)thiophene, THF, $\mathrm{Pd}\left(\mathrm{pph}_{3}\right)_{4}$, reflux; (iii) NBS, DMF, RT; (iv) 2Decyltetradecyl bromide, NaN, DMF, RT; (v) NBS, DMF, RT; (vi) $n$-BuLi, THF, $-78{ }^{\circ} \mathrm{C}$, 2-isopropoxy-4,4,5,5-tetramethyl-1,3,2-dioxaborolane; (vii) $\mathrm{H}_{2} \mathrm{O}_{2}$, acetic acid, $90{ }^{\circ} \mathrm{C}$; (viii) $\mathrm{Bis}$ (pinacolato)diboron, DMF, $\mathrm{KOAc}, \mathrm{PdCl}_{2}\left(\mathrm{dppf}\right.$ ), reflux; (ix) Suzuki polymerization, toluene, $\mathrm{H}_{2} \mathrm{O}, \mathrm{K}_{3} \mathrm{PO}_{4}$, $\mathrm{P}(o-\text { tol })_{3}, \mathrm{Pd}_{2}(\mathrm{dba})_{3}, 90^{\circ} \mathrm{C}$.

tetramethyl-1,3,2-dioxaborolane (58\%) to generate the comonomer. Separately, compound $\mathbf{5}$ was oxidized with hydrogen peroxide under acetic acid (52\%) according to a previously reported protocol $^{28}$ to obtain phenothiazine-S,S-dioxide 7 . Treatment of 7 with bis(pinacolato)diboron under $\mathrm{PdCl}_{2}$ (dppf)/KOAc/DMF led to the phenothiazine-S,S-dioxide diboronic ester 8 in $64 \%$ yield.

With all the monomers ready, Suzuki polycondensations (Scheme 1) were carried out at $90{ }^{\circ} \mathrm{C}$ for $72 \mathrm{~h}$ in degassed toluene/water using $\mathrm{K}_{3} \mathrm{PO}_{4}$ as an organic base, $\mathrm{Pd}_{2}(\mathrm{dba})_{3}$ as a catalyst, and $\mathrm{P}(o \text {-tol })_{3}$ as the corresponding ligand, affording PPTDTBT and PPTDTBT-SS respectively. The target polymers were purified by reprecipitation and Soxhlet extraction with methanol, acetone, and chloroform. They show good solubility in common solvents such as chloroform, dichloromethane, toluene, THF, and chlorobenzene. Note that PPTDTBT-SS has somewhat lower solubility in the nonpolar solvents than that of PPTDTBT because of the increased polarity as well as the hydrophilicity that result from the introduction of the sulfone groups in the polymer backbone. Gel-permeation chromatography (GPC) analysis against polystyrene standard exhibits a number-averaged molecular mass $\left(M_{\mathrm{n}}\right)$ of $9.8 \times 10^{3}$ and $7.6 \times 10^{3} \mathrm{~g} / \mathrm{mol}$ and polydispersity (PDI) of 1.27 and 1.21 for PPTDTBT and PPTDTBT-SS, respectively.

Optical and Electrochemical Properties. The UV-vis spectra of two polymers (PPTDTBT and PPTDTBT-SS) in chloroform solution and solid films on the quartz are shown in Figure 2. The spectroscopic data of the polymers are summarized in Table 1. PPTDTBT film are characterized with a strong, broad and structureless absorption band at 582 $\mathrm{nm}$, corresponding to the intramolecular charge-transfer (ICT) transition, together with a strong absorption band at shorter wavelength $(\sim 395 \mathrm{~nm})$ due to higher energy transitions such as $\pi-\pi^{*}$ transitions. Notably, such optical features are remarkable similarity to those of the analogous PCDTBT $\left(\lambda_{\max }=398\right.$ and $576 \mathrm{~nm})$, but PPTDTBT has a slightly lower optical band gap $\left(E_{\mathrm{g}}{ }^{\text {opt }}=1.79 \mathrm{eV}\right)$ from the absorption edge of the thin film than PCDTBT $(1.88 \mathrm{eV})$. Compared to PPTDTBT showing the absorption maxima, PPTDTBT-SS in the solid state exhibits a nearly identical high-energy peak at $387 \mathrm{~nm}$ but a hypsochromic shift of the ICT band at $535 \mathrm{~nm}$, resulting in a larger optical band gap $(1.95 \mathrm{eV})$. This indicates that, as expected, the donating strength of phenothiazine-S,S-dioxide 

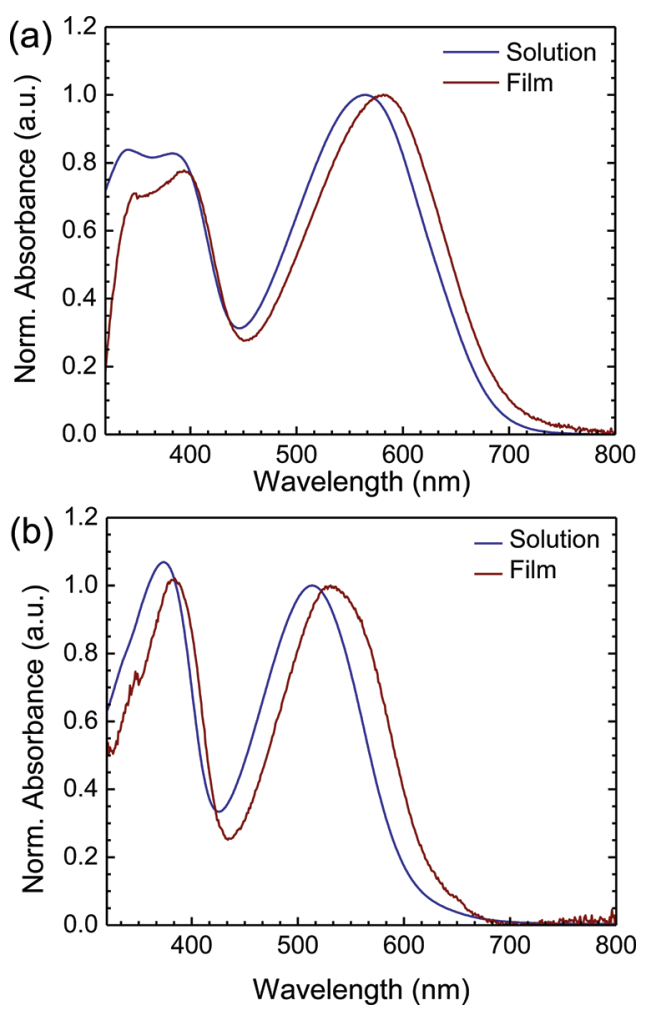

Figure 2. UV-vis absorption spectra of PPTDTBT (a) and PPTDTBT-SS (b).

that contains the electron-withdrawing sulfonyl group is weaker than that of the phenothiazine moiety, leading to relatively reduced ICT character in PPTDTBT-SS.

Electrochemical cyclic voltammetry $(\mathrm{CV})$ was performed to determine the highest occupied molecular orbital (HOMO) and lowest unoccupied molecular orbital (LUMO) energy levels of the polymers (Figure 3). The $\mathrm{CV}$ curves were recorded referenced to an $\mathrm{Ag} / \mathrm{Ag}^{+}\left(0.1 \mathrm{M} n-\mathrm{Bu}_{4} \mathrm{NPF}_{6}\right)$ electrode, which was calibrated by a ferrocene-ferrocenium $\left(\mathrm{Fc} / \mathrm{Fc}^{+}\right)$redox couple $(4.8 \mathrm{eV}$ below the vacuum level). The electrochemical characteristics of the estimated energy levels (HOMO and LUMO) and electrochemical band gap $\left(E_{\mathrm{g}}{ }^{\text {elec }}\right)$ are listed in Table 1. The HOMO and LUMO energy levels are calculated to be -5.41 and $-3.63 \mathrm{eV}$ for PPTDTBT and -5.60 and $-3.60 \mathrm{eV}$ for PPTDTBT-SS, respectively. Considering the relatively low HOMO levels of the polymers, a high $V_{\mathrm{OC}}$ can be expected. ${ }^{29}$ The LUMO levels of the polymers are positioned $0.3 \mathrm{eV}$ above the $\mathrm{PC}_{71} \mathrm{BM}(-4.3 \mathrm{eV})$ to ensure a downhill driving force for charge separation to $\mathrm{PC}_{71} \mathrm{BM}$. The electrochemical HOMO-LUMO gaps of the both polymers are very similar to those of optical band gaps. Apparently, the LUMO value of PPTDTBT matches well with that of PCDTBT $(-3.6$ $\mathrm{eV}$ ) whereas its higher HOMO level, in comparison with PCDTBT $(-5.5 \mathrm{eV})$, indicates the increase of donor strength due to the insertion of the additional electron-rich sulfur atoms. For PPTDTBT-SS interchanged the phenothiazine with a phenothiazine- $S, S$-dioxide segment, the HOMO $(-5.6 \mathrm{eV})$ is found to be lower than of that of PPTDTBT owing to the presence of the electron-deficient $\mathrm{SO}_{2}$ groups in the polymer backbone, which can be beneficial to the better air-stability and higher $V_{\mathrm{OC}}$ of the PSCs based on the polymer as donor. ${ }^{30}$

$\mathrm{X}$-ray Analyses. To evaluate the crystallinity of the polymer, X-ray diffraction (XRD) measurements were taken of thick films prepared from chlorobenzene on $\mathrm{SiO}_{2} / \mathrm{Si}$ substrate. The thickness of the films was determined to be $1.5-55 \mu \mathrm{m}$ by profilometry. Figure 4 shows the XRD data of the thin films of PPTDTBT and PPTDTBT-SS, respectively. PPTDTBT-SS reveals a distinct primary diffraction feature at $2 \theta=4.67^{\circ}$, corresponding to $d$-spacing of $18.9 \AA$ and a secondary broad peak at $2 \theta=21.2^{\circ}(d=4.2 \AA)$ related to $\pi-\pi$ stacking between the polymer main chains is also observed. Contrastingly, the XRD pattern of PPTDTBT exhibits only the secondary broad peak shifting to $17.51^{\circ}(d=5.10 \AA)$. These results suggest a higher structural organization in the solid state for PPTDTBT-SS compared to PPTDTBT.

Organic Field Effect Transistors. To investigate the potential of the two new polymers in plastic electronics, organic field-effect transistors (OFETs) were fabricated in the top contact geometry as described in the Experimental Section (Figure 5). Figure $5 \mathrm{~b}$ shows the transfer characteristics, $\left|I_{d s}\right|$ vs $V_{g s}$ and $\left|I_{d s}\right|^{1 / 2}$ vs $V_{g s}$ (both at $V_{d s}=-60 \mathrm{~V}$ ), of OFETs fabricated using PPTDTBT and PPTDTBT-SS, respectively, as the active layer. These $I_{d s}$ vs $V_{g s}$ curves obtained from both PPTDTBT and PPTDTBT-SS exhibit clear signature of p-type behavior. The saturated charge carrier mobilities of the polymers are calculated using the saturation current equation: $I_{d s}=\left(\mu W C_{i}\right)$ $2 L)\left(V_{g s}-V_{T}\right)^{2} .{ }^{31}$ An hole mobility $(\mu)$ as high as $9.8 \times 10^{-5}$ $\mathrm{cm}^{2} \mathrm{~V}^{-1} \mathrm{~s}^{-1}$ (threshold voltage $\left(V_{T}\right)=-11.5 \mathrm{~V}$ ) with a current on/off ratio $\left(I_{o n} / I_{o f f}\right)$ of $2.5 \times 10^{2}$ is estimated for OFETs produced from PPTDTBT. Interestingly, despite the insertion of the electron-deficient $\mathrm{SO}_{2}$ groups as well as the relatively lower molecular weight, the hole carrier mobility is increased by about 1 order of magnitude in PPTDTBT-SS OFETs $(\mu=6.9$ $\left.\times 10^{-4} \mathrm{~cm}^{2} \mathrm{~V}^{-1} \mathrm{~s}^{-1}, V_{T}=-21.0 \mathrm{~V}, I_{\text {on }} / I_{\text {off }}=7.7 \times 10^{2}\right)$, compared to PPTDTBT. Although a concrete evidence of the high performance with PPTDTBT-SS OFETs is lacking at this stage, we think this is partially contributed either from (i) the reduced contact resistance between the semiconductor and the source/drain electrodes arising from the favorable interfacial dipoles between $S, S$-dioxide groups and Au electrodes or (ii) the well-interconnected thin film morphology due to the interaction between the polar S,S-dioxides. The enhanced intermolecular interactions would bring the polymer chain into a close proximity as evidenced by the XRD results, which can facilitate charge hopping in the polymer.

DFT Electronic Structure Calculations. To shed light on the difference in the electronic properties and energies of

Table 1. UV-Vis Absorption and Electrochemical Properties of the Polymers

\begin{tabular}{lcccccc}
\multicolumn{1}{c}{ polymer } & $\lambda_{\max }[\mathrm{nm}]$ solution & $\lambda_{\max }[\mathrm{nm}]$ film & $E_{\mathrm{g}}^{\text {opt }}(\mathrm{eV})^{a}$ & HOMO $(\mathrm{eV})^{b}$ & $\mathrm{LUMO}^{b}(\mathrm{eV})^{b}$ & $E_{\mathrm{g}}^{\text {elec }}(\mathrm{eV})$ \\
PPTDTBT & 390,564 & 395,582 & 1.79 & -5.41 & -3.63 & 1.78 \\
PPTDTBT-SS & 377,515 & 387,535 & 1.95 & -5.60 & -3.60 & 2.00
\end{tabular}

${ }^{a}$ Calculated from the absorption band edge of the copolymer film, $E_{\mathrm{g}}{ }^{\text {opt }}=1240 / \lambda_{\text {edge }}{ }^{b}$ Thin films in $\mathrm{CH}_{3} \mathrm{CN} / n-\mathrm{Bu}_{4} \mathrm{NPF}_{6}$, versus ferrocenium/ ferrocene at $50 \mathrm{mVs}^{-1}$. HOMO and LUMO estimated from the onset oxidation and reduction potentials, respectively, assuming the absolute energy level of ferrocene/ferrocenium to be $4.8 \mathrm{eV}$ below vacuum. $E_{\mathrm{g}}^{\text {elec }}(\mathrm{eV})=-(\mathrm{LUMO}-\mathrm{HOMO})$. 
(a)

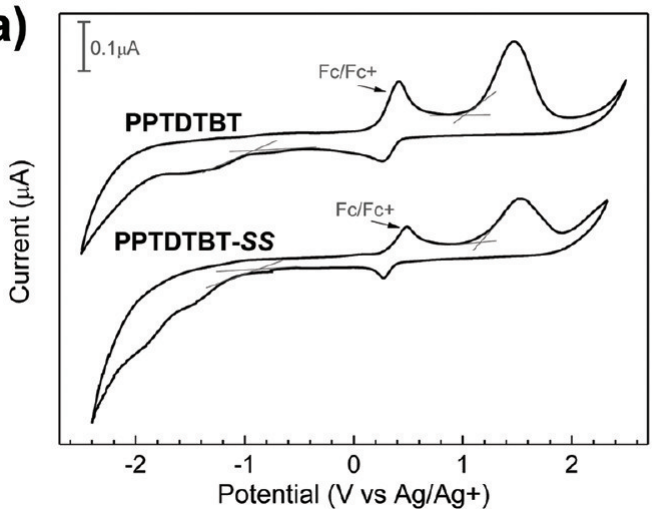

(b)

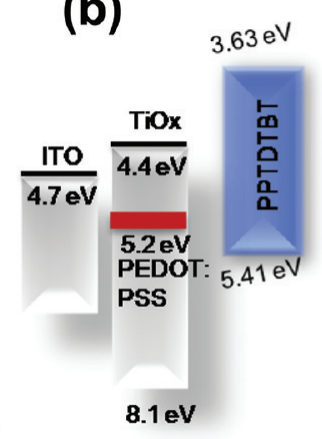

$2.7 \mathrm{eV}$

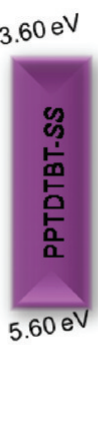

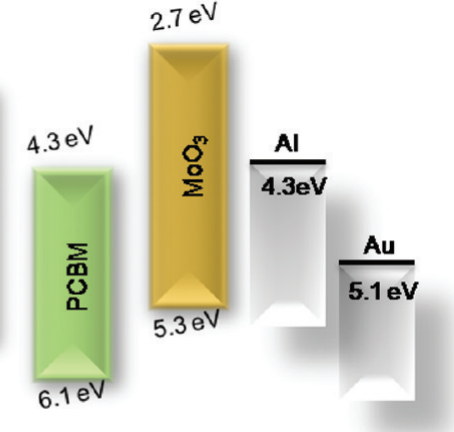

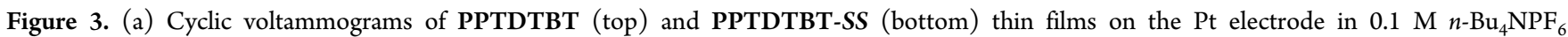
acetonitrile solution at room temperature. (b) Energy level diagrams of individual layers used in conventional and inverted structure.

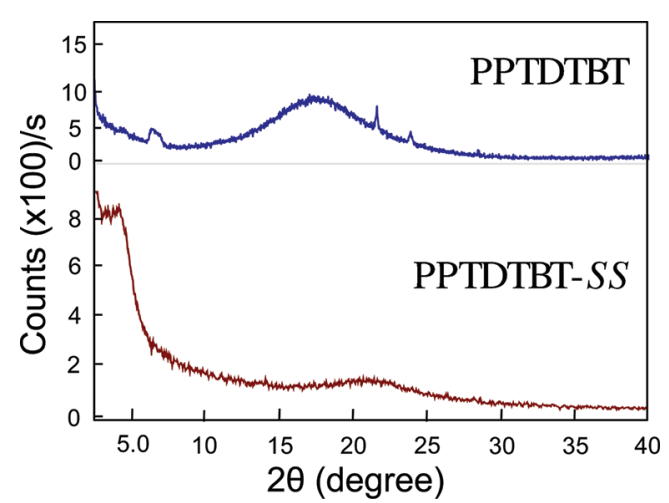

Figure 4. X-ray diffraction (XRD) patterns of drop-cast films of polymers on $\mathrm{SiO}_{2} / \mathrm{Si}$ substrates.

frontier orbitals between the two polymers, computational studies using density functional theory (DFT) approaches were carried out. Oligomers (PTDTBT) ${ }_{n}$ and (PTDTBT-SS $)_{n}$ with $n=1$ and 2 were subjected to the calculations, with the alkyl chains replaced by methyl groups for simplicity. The optimized geometries and electron density distributions of the polymers were calculated with the B3LYP function and $6-31 G^{*}$ basis (Figure 6 and Figure S1 in the Supporting Information). As shown in Figure 6, the HOMO isosurfaces of the both $(\text { PTDTBT })_{n}$ and (PTDTBT-SS $)_{n}$ are well spread over the whole conjugated backbones, whereas the LUMOs are mainly localized on BT units, respectively, which verifies the p-type behaviors obtained from the OFET study. In addition, the calculated bandgaps for (PTDTBT) $)_{2}(1.80 \mathrm{eV})$ and $(\text { PTDTBT-SS })_{2}(1.99 \mathrm{eV})$ are in considerable coincidence with the electrochemical analyses above. It is found that the phenothiazine and phenothiazine-S,S-dioxide rings are folded along the $\mathrm{S} \cdots \mathrm{N}$ vector, having the aspect angles of $21^{\circ}$ and $15^{\circ}$, respectively, in qualitative agreement with their single crystal Xray diffraction studies. ${ }^{28}$ We note a relatively larger dihedral angle between PT and DTBT-SS units $\left(\theta=160^{\circ}\right)$ in the optimized geometry, when compared to that between PT and DTBT $\left(\theta=153^{\circ}\right)$. So it can be seen from the data that the coplanarity of PPTDTBT-SS is better than that in PPTDTBT. This implies that the backbone of PPTDTBT-SS brings about larger effective $\pi-\pi$ interactions in the solid state, which matches qualitatively well with the XRD data. Furthermore, this can explain satisfactorily our interpretation of the better PPTDTBT-SS OFET results above.
Polymer Solar Cells. To demonstrate potential applications of the two polymers in PSCs, we used PPTDTBT and PPTDTBT-SS as an electron donor and $\mathrm{PC}_{71} \mathrm{BM}$ as an electron acceptor and fabricated conventional PSCs with a $\mathrm{BHJ}$ structure of ITO/PEDOT:PSS/polymers:PC ${ }_{71} \mathrm{BM} / \mathrm{Al}$. The main focus of the current study is to elucidate the improved device performance of inverted PSCs by introducing $\mathrm{SO}_{2}$ functionality in the polymer backbone through potential interaction with oxide materials. Thus, the PSCs with inverted configuration stacked from bottom to top (ITO/ $\mathrm{TiO}_{x} /$ polymers: $\mathrm{PC}_{71} \mathrm{BM} / \mathrm{MoO}_{3} / \mathrm{Au}$ ) were also prepared, where $\mathrm{MoO}_{3}$ as the hole transport layer and $\mathrm{TiO}_{x}$ as the electron transport layer were deposited. $\mathrm{TiO}_{x}$ was employed as the electron selective layer due to its high electron affinity (LUMO $=\sim 4.4 \mathrm{eV}) .^{32}$ Since the valence band edge of $\mathrm{TiO}_{x}$ is much lower than those of HOMOs of both the polymers and $\mathrm{PC}_{71} \mathrm{BM}$, the $\mathrm{TiO}_{x}$ layer serves also as a hole blocking layer. Similarly, the $\mathrm{MoO}_{3}$ layer was used to block the electron flow because of its small electron affinity and to enhance hole transport to the anode. ${ }^{33}$ The device structures of regular and inverted polymer solar cells are shown in Figure 1, parts a and $\mathrm{b}$, and Figure $3 \mathrm{~b}$ illustrates the energy level diagrams for each component, respectively. All data were obtained under white light AM1.5G illumination from a calibrated solar simulator with irradiation intensity of $100 \mathrm{~mW} / \mathrm{cm}^{2}$. The active layers through a very broad altering range from 1:1 to $1: 4(\mathrm{w} / \mathrm{w})$ of polymer: $\mathrm{PC}_{71} \mathrm{BM}$ in either chlorobenzene $(\mathrm{CB})$ or $o$ dichlorobenzene (ODCB) were evaluated. The optimized weight ratios of polymer to $\mathrm{PC}_{71} \mathrm{BM}$ for PPTDTBT and PPTDTBT-SS are 1:2 and 1:1.5, respectively. Device current density/voltage $(J-V)$ characteristics are shown in Figure 7 and the parameters listed in Table 2.

PCEs up to $1.69 \%$ is observed for the conventional PPTDTBT:PC ${ }_{71} \mathrm{BM}$ solar cells with a $V_{\mathrm{OC}}$ of $0.77 \mathrm{~V}$, a short circuit current density $\left(J_{\mathrm{SC}}\right)$ of $5.75 \mathrm{~mA} \mathrm{~cm}$, and a fill factor $(F F)$ of $38 \%$. Under the same white light illumination, the PPTDTBT-SS:PC PI $_{71}$ BM-based regular cell exhibits a $J_{S C}$ of 4.03 $\mathrm{mA} \mathrm{cm}{ }^{-2}$, a $V_{\mathrm{OC}}$ of $0.81 \mathrm{~V}$, and a $\mathrm{FF}$ of $30 \%$. It yields a substantially lower PCE of $0.97 \%$ because of its decreased photocurrent, when compared to that of PPTDTBT:PC ${ }_{71} B M$. This can be mainly attributed to PPTDTBT-SS's intrinsic absorption limit in the visible region due to the relatively large energy bandgap. It is worthy to mention that as expected from the oxidation potential, the $V_{\mathrm{OC}}$ for the cell with PPTDTBT-SS is higher than that of PPTDTBT. 

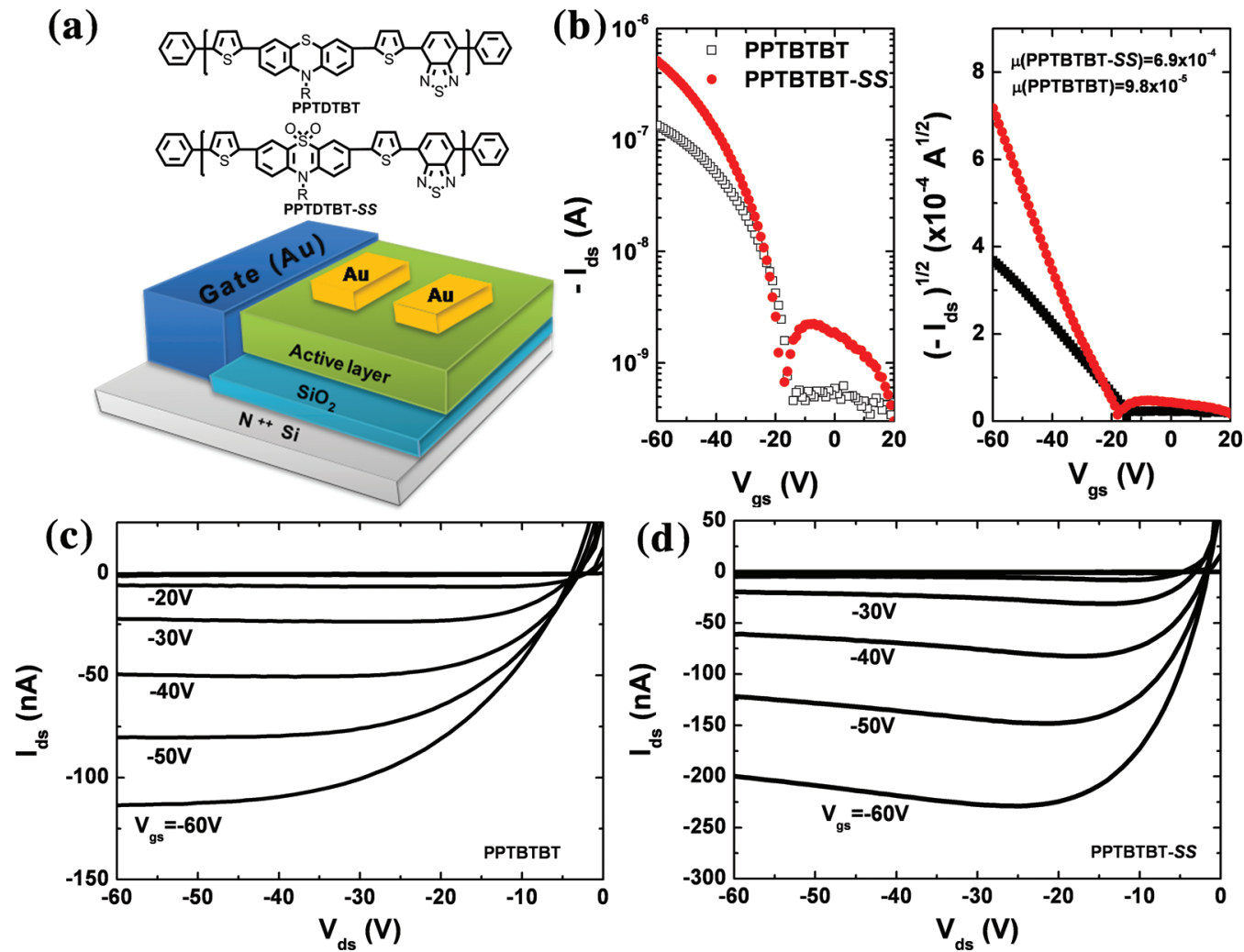

Figure 5. (a) Chemical structures of the polymers and schematic representation of OFETs structure $(L=50 \mu \mathrm{m}, W=1.5 \mathrm{~mm})$. (b) Transfer curves in saturated regime with PPTDTBT (black line) and PPTDTBT-SS (red line). The output characteristics of PPTDTBT (c) and PPTDTBT-SS (d), respectively.
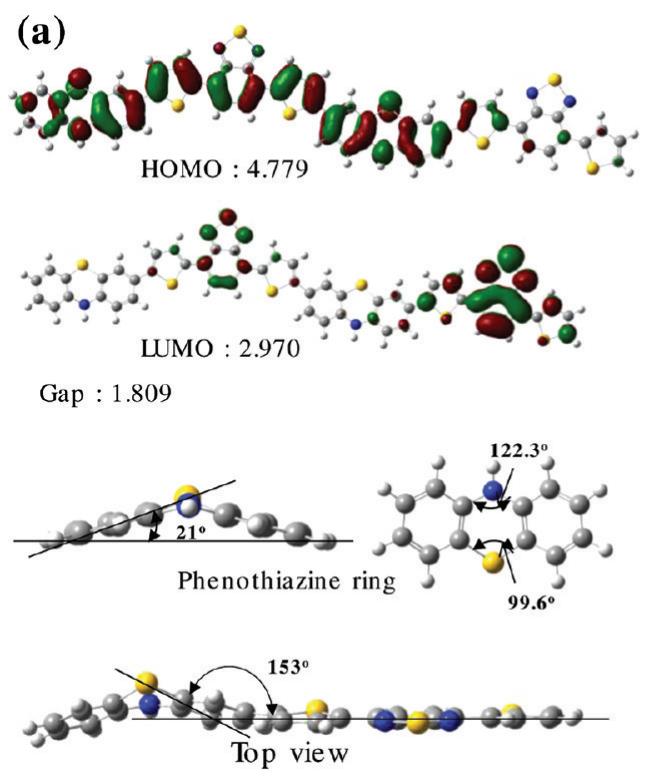

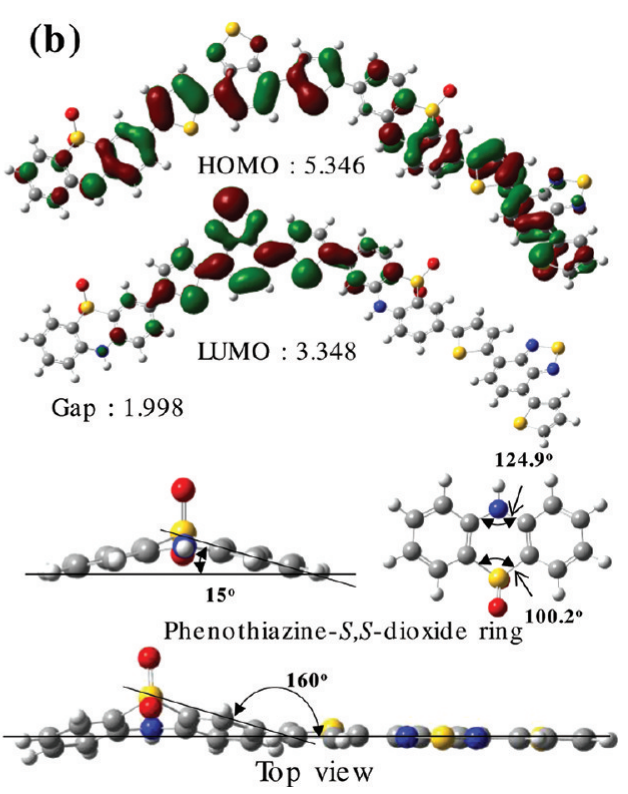

Figure 6. DFT-optimized geometries and charge-density isosurfaces for the HOMO and LUMO levels of (a) (PTDTBT) $)_{2}$ and (b) (PTDTBT-SS) ${ }_{2}$ model systems (top) and optimized structures of phenothiazine and phenothiazine-S,S-dioxide rings and their top views, respectively (bottom).

Despite the aforementioned advantages of the inverted cells, the majority studies on the inverted cells were based on P3HT as active materials, ${ }^{32,34}$ while only few new conjugated polymers had been tested in such configuration. ${ }^{15,35,36}$ Therefore, comparison of the photovoltaic properties of new materials in both conventional and inverted cells is very important to fully evaluate the performance of new polymers. The $J-V$ curves for the inverted polymer solar cells obtained under white light illumination (AM1.5 G, $100 \mathrm{~mW} / \mathrm{cm}^{2}$ ) are shown in Figure 7. The corresponding PCE is 1.47 and $1.22 \%$ for PPTDTBT:PC ${ }_{71} B M$ and PPTDTBT-SS:PC PI1 $_{71}$, respectively (Table 2). In the both inverted devices, despite the fact that the absorption spectra of the active layer films in the two device types are identical, a decrease in the $J_{\mathrm{SC}}\left(4.80 \mathrm{~mA} \mathrm{~cm}^{-2}\right.$ for PPTDTBT:PC ${ }_{71} \mathrm{BM}$ and $4.11 \mathrm{~mA} \mathrm{~cm} \mathrm{~cm}^{-2}$ for PPTDTBT$S S: \mathrm{PC}_{71} \mathrm{BM}$, respectively) is clearly observed, resulting the 

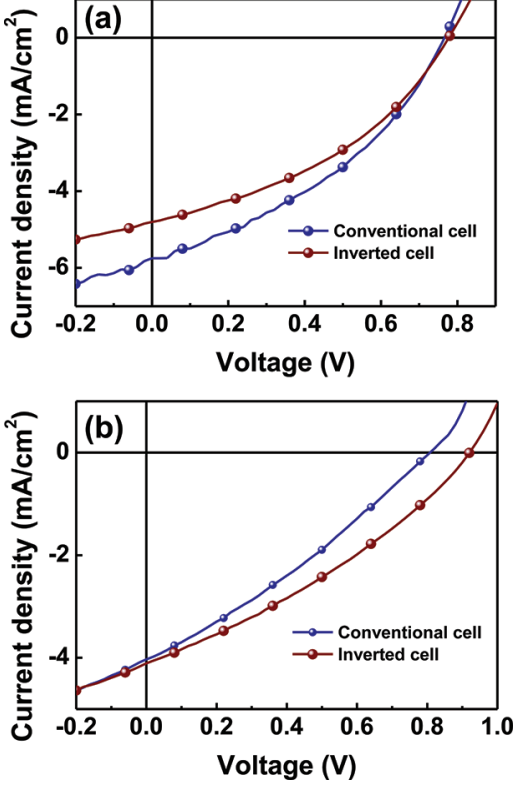

Figure 7. $J-V$ characteristics of the PSCs based on PPTDTBT (a) and PPTDTBT-SS (b) under illumination of AM1.5G, $100 \mathrm{~mW} / \mathrm{cm}^{2}$.

low overall performances. One possible explanation for this phenomenon is that, in the inverted cell, a small fraction of the incident light is observed by the evaporated Au top electrode. It is roughly estimated that $30 \%$ of the incident light with wavelength $<650 \mathrm{~nm}$ is not absorbed by the active layer on the first pass, so clearly the reflectivity of the top electrode plays a non-negligible role in the total number of photons absorbed by the blend. Thus, it is plausible that the enhanced reflectivity of the $\mathrm{Al}$ electrodes used in the normal cell causes the photocurrent to be slightly higher. ${ }^{37}$

Surprisingly, in contrast, the inverted cell of PPTDTBT$S S: \mathrm{PC}_{71} \mathrm{BM}$ exhibits a slight improved $J_{S C}$ and a much higher $V_{\mathrm{OC}}$ value $(0.92 \mathrm{eV})$ than that of the conventional configuration with PPTDTBT:PC ${ }_{71} \mathrm{BM}$, which suggests that the recombination behavior and morphology are different for the two architectures. A likely rationale for this positive effect may be attributed to a combination of the following factors: The hydrophilicity of $\mathrm{SO}_{2}$ groups would facilitate intimate contact on both the electrodes and thus facilitate efficient charge transfer between the active layer and the electrodes. In addition, we cannot rule out that the dipole moment induced by the polar $\mathrm{SO}_{2}$ units in PPTDTBT-SS could be the origin of the improvement in the device performance since a higher $V_{\mathrm{OC}}$ can indicate a larger electrostatic field across the device structure, ${ }^{32}$ although other explanations are still possible. Further investigation of these films using electrostatic force and surface potential microscopy in underway.

The accuracy of the photovoltaic measurements can be confirmed by the incident photon-to-electron conversion efficiency (IPCE) of the devices. Figure 8 shows the IPCE curves of both the conventional and inverted PSCs fabricated under the optimized conditions as those used for the $J-V$

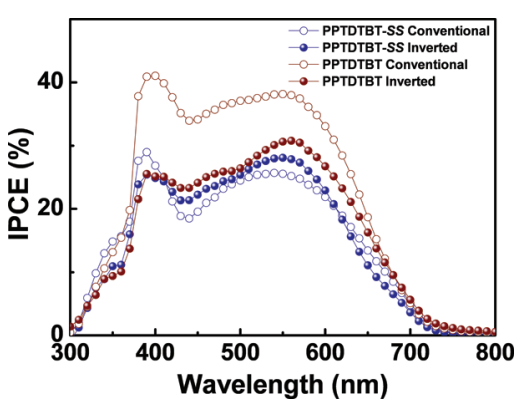

Figure 8. Incident photon-to-current efficiency (IPCE) spectra of the polymer: $\mathrm{PC}_{71} \mathrm{BM}$ solar cells.

measurements. All devices show a broad photoresponse spreading from 300 to $700 \mathrm{~nm}$, with maximum around 570 $\mathrm{nm}$. However, the IPCE of the device is within $40 \%$ for almost the whole absorption range. From this observation, we believe that the IPCE of the devices can be improved by increasing the thickness of the active layer without hampering charge separation and transport properties. However, because of their more or less limited solubility for the fabrication of practical PSCs, it is difficult to obtain high thickness for the active layer by using high concentration of the polymer blends. Currently, the preparation of dithienylbenzothiadiazole with two flexible alkoxyl chains in an effort to improve solubility is ongoing. Obviously, the IPCE value for the conventional PPTDTBT: $\mathrm{PC}_{71} \mathrm{BM}$ is the highest, which agrees with the highest $J_{S C}$ value of the devices. To evaluate the accuracy of the photovoltaic results, the $J_{S C}$ values were calculated by integrating the IPCE data with the AM 1.5G reference spectrum. The $J_{\mathrm{SC}}$ values obtained using integration and $J-V$ measurements are rather close (within 7\% error), which indicates that the photovoltaic results are reliable.

Morphology. The nanoscale morphologies of both the conventional and inverted polymer $/ \mathrm{PC}_{71} \mathrm{BM}$ films were studied using tapping-mode atomic force microscopy (AFM). Surface topography (left) and phase images (right) were taken for each film and are shown in Figure 9. Both the regular and inverted PPTDTBT:PC ${ }_{71}$ BM blends are very similar and exhibit a rather uniform smooth film formation which suggests the absence of large features that might reduce the interface between polymer and fullerene potentially limiting device performance. ${ }^{38,39}$ In contrast, PPTDTBT-SS:PC ${ }_{71} \mathrm{BM}$ blends in both conventional and inverted structures (Figure 9, c and d) give very inhomogeneous features in which voids with a diameter of $\sim 300 \mathrm{~nm}$ are present. This indicates poor miscibility between PPTDTBT-SS and $\mathrm{PC}_{71} \mathrm{BM}$. This implies that the presence of $\mathrm{SO}_{2}$ groups makes PPTDTBT-SS strongly hydrophilic, which

Table 2. Photovoltaic Performance of Blends of the Polymers with Fullerenes

\begin{tabular}{ll} 
device structure & \multicolumn{1}{c}{ composite } \\
conventional & PPTDTBT:PC ${ }_{71} \mathrm{BM}(1: 2)$ \\
& PPTDTBT-SS:PC ${ }_{71} \mathrm{BM}(1: 1.5)$ \\
inverted & PPTDTBT:PC ${ }_{71} \mathrm{BM}(1: 2)$ \\
& PPTDTBT-SS:PC PC $_{71} \mathrm{BM}(1: 1.5)$
\end{tabular}

$\begin{array}{cc}d(\mathrm{~nm})^{a} & J_{\text {SC }}\left(\mathrm{mA} \mathrm{cm}^{-2}\right) \\ 50 & 5.75 \\ 50 & 4.03 \\ 28 & 4.80 \\ 32 & 4.11\end{array}$

$V_{\mathrm{OC}}(\mathrm{V})$
0.77
0.81
0.78
0.92

$\begin{array}{cc}\text { FF } & \text { PCE (\%) } \\ 0.38 & 1.69 \\ 0.30 & 0.97 \\ 0.39 & 1.47 \\ 0.32 & 1.22\end{array}$

${ }^{a_{\text {Thickness }}}$ of the active layer. 

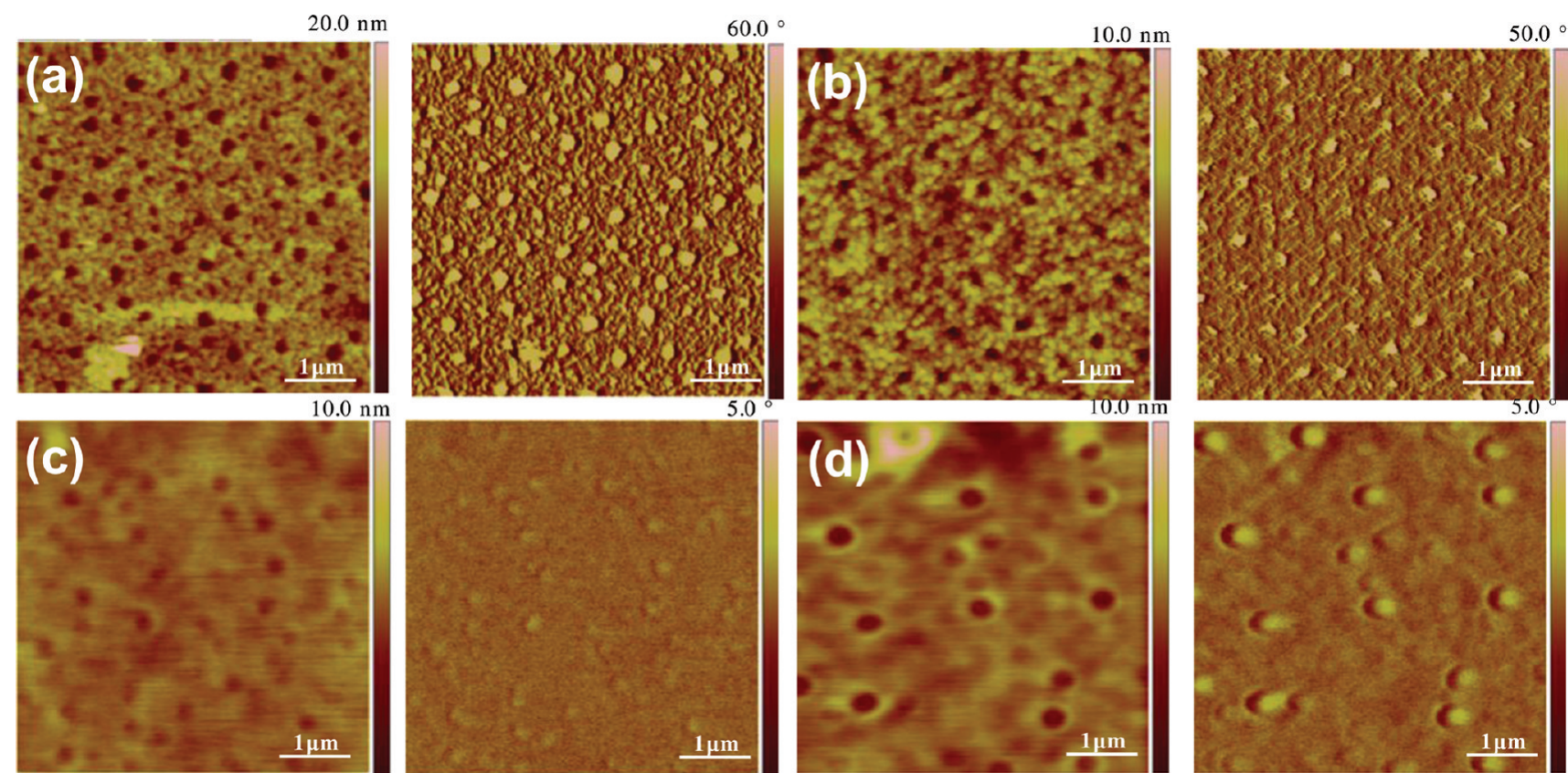

Figure 9. Tapping-mode AFM images $(5 \mu \mathrm{m} \times 5 \mu \mathrm{m})$ of PPTDTBT:PC ${ }_{71} \mathrm{BM}$ (conventional (a); inverted (b)) and PPTDTBT-SS:PC ${ }_{71} \mathrm{BM}$ (conventional (c); inverted (d)) films used in making the devices (under optimized device conditions). The topography of each film is shown in the left panels, and the corresponding phase images in the right panels.

is, in large part, responsible for the relatively low PCEs in the conventional cells, but this can positively affect the inverted PSCs adopting transporting metal oxides between the ITO/ $\mathrm{BHJ}$ and $\mathrm{BHJ} /$ metal interfaces because of the potential interaction with oxides. This observation is in good agreement with the $J-V$ characteristics tested in this study.

\section{CONCLUSIONS}

Considering low cost PSCs into account, an easily accessible donor, phenothiazine, which is stronger than commonly used 2,7-carbazole donors due to an additional sulfur atom, has been copolymerized with electron-deficient benzothiadiazole building block to yield new conjugated polymer PPTDTBT. By virtue of the enhanced strength of ICT, the "strong donoracceptor" polymer (PPTDTBT) shows more bathocromically shifted absorption spectrum $\left(\lambda_{\max }=582 \mathrm{~nm}\right)$ and lower band gap $\left(E_{\mathrm{g}}^{\text {elec }}=1.78 \mathrm{eV}\right)$ in comparison with its analogous polymer (PCDTBT) that in particular has been subject to increasing interest in the polymer research community. Through the sulfur oxidation in the phenothiazine unit, the corresponding oxidized form polymer PPTDTBT-SS is also prepared and characterized in parallel following our design motif. The strong polarity of $\mathrm{SO}_{2}$ groups would enhance the compatibility and low contact resistance in the inverted $\mathrm{BHJ}$ solar cells integrated two metal oxides. Both the PPTDTBT and PPTDTBT-SS show moderate mobilities as p-type polymer semiconductors in OFETs. Interestingly, the carrier mobility of PPTDTBT-SS is about 1 order of magnitude higher than that of PPTDTBT, which is presumably ascribed to the closer packing driven either from the dipolar intermolecular interactions associated with the presence of the sulfonyl groups or the relatively enhanced coplanarity of PPTDTBT-SS, supported by the DFT calculations as well as XRD results. The performance of the PSCs containing the polymer PPTDTBT reaches PCEs of $1.69 \%$ and $1.47 \%$ for conventional and inverted structure devices when using $\mathrm{PC}_{71} \mathrm{BM}$ as electron acceptor, respectively.
On the other hand, despite the fact that relatively low-lying HOMO of PPTDTBT-SS enhances the $V_{\mathrm{OC}}$, the current

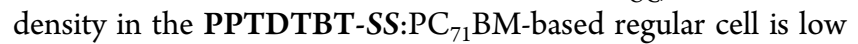
and limits the PCE to $0.97 \%$. This is likely a consequence of a reduced solar absorption of PPTDTBT-SS's caused by the relatively large energy bandgap. Delightfully, when it comes to incorporating PPTDTBT-SS into the inverted configuration cell with $\mathrm{TiO}_{x}$ and $\mathrm{MoO}_{3}$ as electron-selective and holeselective layers, respectively, the estimated PCE of $1.22 \%$ is achieved from the combination with the improved $V_{\mathrm{OC}}$ and $J_{\mathrm{SC}}$. Current work on $\pi$-conjugated polymer structural modification has been aimed at understanding the influence of polymer polarity in inverted solar cells. Our results indicate that the introduction of $S, S$-dioxide units into the polymer backbone is a useful strategy for the design of high performance inverted solar cells.

\section{EXPERIMENTAL SECTION}

Materials and Instruments. All starting materials were purchased either from Aldrich or Acros and used without further purification. THF was distilled over sodium/benzophenone. ${ }^{1} \mathrm{H}$ NMR and ${ }^{13} \mathrm{C}$ NMR spectra were recorded on a Varian VNRS $600 \mathrm{MHz}$ (Varian USA) spectrophotometer using $\mathrm{CDCl}_{3}$ as solvent and tetramethylsilane (TMS) as the internal standard and MALDI MS spectra were obtained from Ultraflex III (Bruker, Germany). UV-vis-NIR spectra were taken on Cary 5000 (Varian USA) spectrometer. Numberaverage $\left(M_{n}\right)$ and weight-average $\left(M_{w}\right)$ molecular weights, and polydispersity index (PDI) of the polymer products were determined by gel permeation chromatography (GPC) with Agilent 1200 HPLC Chemstation using a series of mono disperse polystyrene as standards in THF (HPLC grade) at $308 \mathrm{~K}$. Cyclic voltammetry (CV) measurements were performed on AMETEK VersaSTAT 3 with a three-electrode cell in a nitrogen bubbled $0.1 \mathrm{M}$ tetra- $n$-butylammonium hexafluorophosphate $\left(n-\mathrm{Bu}_{4} \mathrm{NPF}_{6}\right)$ solution in acetonitrile at a scan rate of $50 \mathrm{mV} / \mathrm{s}$ at room temperature. A used as the $\mathrm{Ag} / \mathrm{Ag}^{+}(0.1$ $\mathrm{M}$ of $\mathrm{AgNO}_{3}$ in acetonitrile) reference electrode, platinum counter electrode and polymer-coated platinum working electrode, respectively. The $\mathrm{Ag} / \mathrm{Ag}^{+}$reference electrode was calibrated using a 
ferrocene/ferrocenium redox couple as an internal standard, whose oxidation potential is set at $-4.8 \mathrm{eV}$ with respect to zero vacuum level. The HOMO energy levels were obtained from the equation HOMO = $-\left(E_{\mathrm{ox}}{ }^{\text {onset }}-E_{\text {(ferrocene) }}{ }^{\text {onset }}+4.8\right) \mathrm{eV}$. The LUMO levels of polymers were obtained from the equation LUMO $=-\left(E_{\text {red }}{ }^{\text {onset }}-E_{\text {(ferrocene })}{ }^{\text {onset }}\right.$ $+4.8) \mathrm{eV}$.

OFET Device Preparation and Measurement. All p-type OFETs were fabricated on heavily doped n-type silicon $(\mathrm{Si})$ wafers each covered with a thermally grown silicon dioxide $\left(\mathrm{SiO}_{2}\right)$ layer with thickness of $200 \mathrm{~nm}$. The doped Si wafer acts as a gate electrode, and the $\mathrm{SiO}_{2}$ layer functions as the gate insulator. The active layer was deposited by spin-coating at $2500 \mathrm{rpm}$. All solutions were prepared at 0.5 wt \% concentration in chlorobenzene. The thickness of the deposited films was about $60 \mathrm{~nm}$. Prior to vapor-deposition of sourcedrain electrodes, the films were dried on a hot plate stabilized at $80^{\circ} \mathrm{C}$ for $30 \mathrm{~min}$. All fabrication processes were carried out in a glovebox filled with $\mathrm{N}_{2}$. Source and drain electrodes using Au were deposited by thermal evaporation using a shadow mask. The thickness of source and drain electrodes was $50 \mathrm{~nm}$. Channel length $(\mathrm{L})$ and channel width (W) was $50 \mu \mathrm{m}$ and $1.5 \mathrm{~mm}$, respectively. Electrical characterization was performed using a Keithley semiconductor parametric analyzer (Keithley 4200) under $\mathrm{N}_{2}$ atmosphere. The electron mobility $(\mu)$ was determined using the following equation in the saturation regime

$$
I_{d s}=\left(W C_{i} / 2 L\right) \times \mu \times\left(V_{g s}-V_{T}\right)^{2}
$$

where $C_{i}$ is the capacitance per unit area of the $\mathrm{SiO}_{2}$ dielectric $\left(C_{i}=15\right.$ $\mathrm{nF} / \mathrm{cm}^{2}$ ) and $V_{T}$ is the threshold voltage.

Fabrication of Conventional and Inverted Photovoltaic Cells. Two-type photovoltaic cells were fabricated on ITO-coated glass substrates. The ITO-coated glass substrates were first cleaned with detergent, ultrasonicated in water, acetone and isopropyl alcohol, and dried overnight in an oven. In conventional cells, PEDOT:PSS(Al 4083) was spin-cast on cleaned ITO substrates after a UV-ozone treatment for $15 \mathrm{~min}$ and heated at $140{ }^{\circ} \mathrm{C}$ for $10 \mathrm{~min}$ in air. Subsequently, the active layer was coated in a glovebox. The solution containing a mixture of PPTDTBT:PC ${ }_{71} \mathrm{BM}(1: 2)$ in a solvent (chlorobenzene) with a concentration of $11 \mathrm{mg} / \mathrm{mL}$ and PPTBTDT$S S: \mathrm{PC}_{71} \mathrm{BM}(1: 1.5)$ in a solvent (dichlorobenzene) with a concentration of $13 \mathrm{~g} / \mathrm{mL}$ was spin-cast on top of PEDOT:PSS film. After then, the top electrode ( $\mathrm{Al})$ was deposited on the active layer in a vacuum $\left(<10^{-6}\right.$ Torr $)$ thermal evaporator. Inverted solar cells were fabricated on ITO-coated glass substrates. A $\mathrm{TiO}_{x}$ precursor solution was prepared using the sol-gel method. The $\mathrm{TiO}_{x}$ precursor solution was spin-cast on cleaned ITO substrates after a UV-ozone treatment for $15 \mathrm{~min}$ and heated at $80{ }^{\circ} \mathrm{C}$ for $10 \mathrm{~min}$ in air for conversion to $\mathrm{TiO}_{x}$ by hydrolysis. Subsequently, the $\mathrm{TiO}_{x}$-coated substrates were transferred into a glovebox. A solution containing a mixture of PPTDTBT:PC ${ }_{71} \mathrm{BM}(1: 2)$ in a solvent (chlorobenzene) with a concentration of $11 \mathrm{mg} / \mathrm{mL}$ was spin-cast on top of $\mathrm{TiO}_{x}$ films at 1500 $\mathrm{rpm} 60 \mathrm{~s}$ and PPTBTDT-SS:PC $\mathrm{P}_{71} \mathrm{BM}(1: 1.5)$ in a solvent (dichlorobenzene) with a concentration of $13 \mathrm{~g} / \mathrm{mL}$ was spin-cast on top of $\mathrm{TiO}_{x}$ films at $600 \mathrm{rpm} 60 \mathrm{~s}$. Then, a thin layer of $\mathrm{MoO}_{3}$ film $(\approx 5 \mathrm{~nm})$ was evaporated on top of the active layer. Finally, the anode $(\mathrm{Au}, \approx 95 \mathrm{~nm})$ was deposited on the active layer in a vacuum $\left(<10^{-6}\right.$ Torr) thermal evaporator. The cross-sectional area of each of the electrode defines the active area of the device as $13.5 \mathrm{~mm}^{2}$. Photovoltaic cell measurements were carried out inside the glovebox using a high quality optical fiber to guide the light from the solar simulator equipped with a Keithley 2635A source measurement unit. The $J-V$ curves for the devices were measured under AM 1.5G illumination at $100 \mathrm{~mW} \mathrm{~cm}$. The IPCE spectra for the PSCs were measured on an IPCE measuring system.

Synthesis of $\mathbf{N}$-2-Decyltetradecylphenothiazine (4). To a mixture of phenothiazine $(6.2 \mathrm{~g}, 31.1 \mathrm{mmol})$ and sodium hydride (60\% in mineral oil, $1.0 \mathrm{~g}, 41.7 \mathrm{mmol}$ ) in anhydrous DMF $(40 \mathrm{~mL})$, 2decyltetradecyl bromide $(16.8 \mathrm{~g}, 40.2 \mathrm{mmol})$ was slowly added at room temperature under argon. The mixture was stirred at room temperature overnight, which was poured into water and extracted with diethyl ether. The separated organic layer was dried over $\mathrm{MgSO}_{4}$ and removed under reduced pressure. The crude product was purified by column chromatography (silica gel, hexane) to afford $13.6 \mathrm{~g}(82 \%)$ of 4 as a colorless oil. ${ }^{1} \mathrm{H}$ NMR $\left(600 \mathrm{MHz}, \mathrm{CDCl}_{3}\right): \delta(\mathrm{ppm}) 7.14(\mathrm{~m}$, $4 \mathrm{H}), 6.92-6.86(\mathrm{~m}, 4 \mathrm{H}), 3.73(\mathrm{~d}, 2 \mathrm{H}, J=6.6 \mathrm{~Hz}), 2.00(\mathrm{~m}, 1 \mathrm{H})$, $1.41-1.26(\mathrm{~m}, 40 \mathrm{H}), 0.91-0.88(\mathrm{t}, 6 \mathrm{H}, J=7.2 \mathrm{~Hz}) .{ }^{13} \mathrm{C}$ NMR $(150$ $\left.\mathrm{MHz}, \mathrm{CDCl}_{3}\right): \delta(\mathrm{ppm}) 145.94,127.66,127.17,126.03,122.43$, $116.05,51.65,36.25,34.60,32.10,31.81,30.11,29.94,29.86,29.83$, $29.81,29.80,29.77,29.74,29.73,29.63,29.62,29.53,29.51,28.00$, 26.40, 22.86, 14.29, 14.27. Anal. Calcd: C, 80.68; H, 10.72; N, 2.61; S, 5.98. Found: C: $80.91, \mathrm{H}: 10.82, \mathrm{~N}: 2.74, \mathrm{~S}: 5.71$. MALDI-TOF-MS $\mathrm{m} / z:[\mathrm{M}]^{+\bullet}=535.34$; calcd, 535.91 .

Synthesis of 3,7-Dibromo- $\mathrm{N}$-2-decyltetradecylphenothiazine (5). $N$-Bromosuccinimide $(3.65 \mathrm{~g}, 20.53 \mathrm{mmol}$ ) was slowly added to a solution of $4(5.0 \mathrm{~g}, 9.33 \mathrm{mmol})$ in anhydrous DMF (50 $\mathrm{mL}$ ). The reaction mixture was stirred at room temperature overnight, which was quenched by water and extracted with diethyl ether. The separated organic layer was washed with water and brine, then dried over $\mathrm{MgSO}_{4}$. The solvent was removed under reduced pressure. The crude product was purified by column chromatography(silica gel, hexane) to afford $6.0 \mathrm{~g}(93 \%)$ of 5 as a yellow oil. ${ }^{1} \mathrm{H}$ NMR (600 $\left.\mathrm{MHz}, \mathrm{CDCl}_{3}\right): \delta(\mathrm{ppm}) 7.25(\mathrm{~m}, 4 \mathrm{H}), 6.69(\mathrm{~d}, 2 \mathrm{H}, J=1.8 \mathrm{~Hz}), 3.64$ $(\mathrm{d}, 2 \mathrm{H}, J=7.2 \mathrm{~Hz}), 1.89(\mathrm{~m}, 1 \mathrm{H}), 1.36-1.22(\mathrm{~m}, 40 \mathrm{H}), 0.89(\mathrm{t}, 6 \mathrm{H}, J$ $=7.2 \mathrm{~Hz}) \cdot{ }^{13} \mathrm{C}$ NMR $\left(150 \mathrm{MHz}, \mathrm{CDCl}_{3}\right): \delta(\mathrm{ppm}) 144.75,130.20$, $129.99,127.49,117.30,114.91,51.88,34.60,32.09,32.08,31.66$, $30.06,29.85,29.82,29.77,29.75,29.59,29.52,29.50,26.33,22.85$, 14.28. Anal. Calcd: C, 62.33; H, 7.99; Br, 23.04; N, 2.02; S, 4.62. Found: C: $63.34, \mathrm{H}: 8.11, \mathrm{~N}: 2.17, \mathrm{~S}: 4.53$. MALDI-TOF-MS $\mathrm{m} / z$ : $[\mathrm{M}]^{+\bullet}=693.17$; calcd, 693.7.

Synthesis of $\mathrm{N}$-2-Decyltetradecyl-3,7-bis(4,4,5,5-tetramethyl-1,3,2-dioxaborolanyl)phenothiazine (6). A portion of $4.43 \mathrm{~mL}$ of $n$-butyllithium ( $1.6 \mathrm{M}$ in hexane, $7.08 \mathrm{mmol})$ was added dropwise to a solution of $5(2.0 \mathrm{~g}, 2.83 \mathrm{mmol})$ in anhydrous THF $(40 \mathrm{~mL})$ under argon atmosphere at $-78{ }^{\circ} \mathrm{C}$. After $30 \mathrm{~min}$, 2-isopropoxy-4,4,5,5tetramethyl-1,3,2-dioxaborolane $(1.32 \mathrm{~mL}, 7.08 \mathrm{mmol})$ was injected to the reaction mixture. The resulting mixture was warmed up to room temperature and stirred overnight. Then, the reaction was quenched by water and extracted with a diethyl ether. The separated organic layer was washed with water and brine, then dried over $\mathrm{MgSO}_{4}$ and removed under reduced pressure. The crude product was purified by column chromatography (silica gel, $10 \%$ ethyl acetate in hexane) to afford $1.3 \mathrm{~g}(58 \%)$ as a yellow-green sticky solid. ${ }^{1} \mathrm{H}$ NMR $(600 \mathrm{MHz}$, $\left.\mathrm{CDCl}_{3}\right): \delta(\mathrm{ppm}) 7.56(\mathrm{~d}, 4 \mathrm{H}, J=7.8 \mathrm{~Hz}), 6.83(\mathrm{~d}, 2 \mathrm{H}, J=7.8 \mathrm{~Hz})$, $3.74(\mathrm{~d}, 2 \mathrm{H}, J=6.6 \mathrm{~Hz}), 1.94(\mathrm{~m}, 1 \mathrm{H}), 1.37-1.2(\mathrm{~m}, 64 \mathrm{H}), 0.89(\mathrm{t}$, $6 \mathrm{H}, J=6.6 \mathrm{~Hz}) \cdot{ }^{13} \mathrm{C}$ NMR $\left(150 \mathrm{MHz}, \mathrm{CDCl}_{3}\right): \delta(\mathrm{ppm})$ 148.07, $134.07,133.98,125.27,115.46,83.80,34.79,32.09,32.07,31.78$, 30.11, 29.81, 29.75, 29.62, 29.51, 29.48, 26.43, 24.99, 22.48. Anal. Calcd: C, 73.18; H, 10.11; B, 2.74; N, 1.78; O, 8.12; S, 4.07; Found: C: 73.44, H: 10.01, N: 1.94, S: 3.86, O: 7.82. MALDI-TOF-MS $\mathrm{m} / z$ : $[\mathrm{M}]^{\bullet}=787.53$; calcd, 787.83 .

Synthesis of 3,7-Dibromo-N-2-decyltetradecylphenothiazine-S,S-dioxide (7). Hydroperoxide $(35 \%, 10 \mathrm{~mL})$ was added dropwise to a solution of $5(2 \mathrm{~g}, 2.9 \mathrm{mmol})$ in acetic acid $(30 \mathrm{~mL})$ was stirred at $90{ }^{\circ} \mathrm{C}$ overnight. After cooled down, the water was added and extracted with ethyl acetate. The separated organic layer was and washed with water and brine, then dried over $\mathrm{MgSO}_{4}$ and removed under reduced pressure. The crude product was purified by column chromatography (silica gel, $10 \%$ ethyl acetate in hexane) to afford $1.1 \mathrm{~g}$ $(52 \%)$ of 7 as a colorless solid. ${ }^{1} \mathrm{H}$ NMR $\left(600 \mathrm{MHz}, \mathrm{CDCl}_{3}\right): \delta(\mathrm{ppm})$ $8.17(\mathrm{~d}, 2 \mathrm{H}, J=2.4 \mathrm{~Hz}), 7.67(\mathrm{~d}, 2 \mathrm{H}, J=7.2 \mathrm{~Hz}), 7.24(\mathrm{~s}, 2 \mathrm{H}), 4.04$ $(\mathrm{d}, 2 \mathrm{H}, J=6.6 \mathrm{~Hz}), 1.94(\mathrm{~m}, 1 \mathrm{H}), 1.29-1.20(\mathrm{~m}, 40 \mathrm{H}), 0.89(\mathrm{t}, 6 \mathrm{H}, J$ $=7.2 \mathrm{~Hz}) \cdot{ }^{13} \mathrm{C}$ NMR $\left(150 \mathrm{MHz}, \mathrm{CDCl}_{3}\right): \delta(\mathrm{ppm}) 140.83,135.92$, $126.99,126.41,119.03,114.72,32.06,30.90,29.95,29.84,29.80$, 29.74, 29.71, 29.62, 29.51, 29.49, 26.22, 22.84, 14.27. Elemental Analysis: C, 59.58; H, 7.64; Br, 22.02; N, 1.93; O, 4.41; S, 4.42; Found: C: 59.84, H: 7.70, N: 2.01, S: 4.21, O: 4.22. MALDI-TOF-MS $\mathrm{m} / z:[\mathrm{M}]^{+\bullet}=727.23$; calcd, 725.7

Synthesis of N-2-decyltetradecyl-3,7-bis(4,4,5,5-tetramethyl-1,3,2-dioxaborolanyl)phenothiazine-S,S-dioxide (8). Compound $7(0.7 \mathrm{~g}, 0.96 \mathrm{mmol})$, bis(pinacolato)diboron $(0.97 \mathrm{~g}, 3.84$ $\mathrm{mmol})$, potassium acetate $(0.66 \mathrm{~g}, 6.72 \mathrm{mmol})$, and $\mathrm{Pd} \mathrm{Cl}_{2}(\mathrm{dppf})(42$ 
$\mathrm{mg}, 57.6 \mu \mathrm{mol})$ in anhydrous DMF $(20 \mathrm{~mL})$ were stirred at $120{ }^{\circ} \mathrm{C}$ overnight. The reaction was quenched by water and extracted with ethyl acetate. The separated organic layer was washed with water and brine, then dried over $\mathrm{MgSO}_{4}$ and removed under reduced pressure. The crude product was purified by column chromatography (silica gel, $30 \%$ ethyl acetate in hexane) to afford $0.5 \mathrm{~g}(64 \%)$ of 8 as light-yellow solid. ${ }^{1} \mathrm{H}$ NMR $\left(600 \mathrm{MHz}, \mathrm{CDCl}_{3}\right): \delta(\mathrm{ppm}) 8.58(\mathrm{~s}, 2 \mathrm{H}), 7.97(\mathrm{~d}$, $2 \mathrm{H}, J=8.4 \mathrm{~Hz}), 7.33(\mathrm{~d}, 2 \mathrm{H}, J=8.4 \mathrm{~Hz}), 4.13(\mathrm{~d}, 2 \mathrm{H}, J=7.2 \mathrm{~Hz})$, $1.98(\mathrm{~m}, 1 \mathrm{H}), 1.35-1.19(\mathrm{~m}, 64 \mathrm{H}), 0.88(\mathrm{t}, 6 \mathrm{H}, J=7.2 \mathrm{~Hz}) .{ }^{13} \mathrm{C}$ NMR $\left(150 \mathrm{MHz}, \mathrm{CDCl}_{3}\right): \delta$ (ppm) 143.64, 138.72, 131.02, 125.88, 116.21, 84.28, 32.08, 31.05, 29.99, 29.80, 29.71, 29.67, 29.51, 29.47, 25.18, 25.02, 22.84, 14.28. Anal. Calcd: C: 70.32, H: 9.71, B: 2.64, N: 1.71, O: 11.71, S: 3.91. Found: C: 70.52, H: 9.68, N: 1.88, S: 3.61, O: 11.62. MALDI-TOF-MS $m / z:\left[\mathrm{M}^{+\bullet}=819.53\right.$; calcd, 819.83.

Poly(N-(2-decyltetradecyl)-3,7-phenothiazine-alt-5,5-(4', $7^{\prime}$ di-2-thienyl-2', 1' $^{\prime} \mathbf{3}^{\prime}$-benzothiadiazole)) (PPTDTBT). In a Schlenk flask, monomer $6(0.21 \mathrm{~g}, 0.266 \mathrm{mmol})$ and 4,7-bis(5-bromothiophenyl)-2,1,3-benzothiadiazole $(0.12 \mathrm{~g}, 0.266 \mathrm{mmol})$ was dissolved in toluene $(7 \mathrm{~mL})$, to this a solution of $\mathrm{K}_{3} \mathrm{PO}_{4}(286 \mathrm{mg}, 1.34 \mathrm{mmol})$, triotolylphosphine $(10 \mathrm{mg}, 0.03 \mathrm{mmol})$ and deionized water $(1.5 \mathrm{~mL})$ was added. The mixture was vigorously stirred at room temperature under argon. After $30 \mathrm{~min}, \mathrm{Pd}_{2}(\mathrm{dba})_{3}(10 \mathrm{mg}, 0.011 \mathrm{mmol})$ was added to the reaction mixture and stirred at $90{ }^{\circ} \mathrm{C}$ for 3 days (end-capped with phenylboronic acid and bromobenzene). Finally, the solution was precipitated in a mixture of methanol and ammonia $(4: 1 \mathrm{v} / \mathrm{v}, 250 \mathrm{~mL})$. This was filtered off through $0.45 \mu \mathrm{m}$ nylon filter, washed on Soxhlet apparatus with methanol $(1 \mathrm{~d})$ and acetone $(1 \mathrm{~d})$. Then, $160 \mathrm{mg}$ $(72 \%)$ of the polymer was recovered as a violet-powder $\left(M_{\mathrm{n}}=9.8 \times\right.$ $\left.10^{3} \mathrm{~g} / \mathrm{mol}, \mathrm{PDI}=1.27\right) .{ }^{1} \mathrm{H}$ NMR $\left(600 \mathrm{MHz}, \mathrm{CDCl}_{3}\right): \delta(\mathrm{ppm}) 8.11$ (br, $2 \mathrm{H}), 7.88(\mathrm{br}, 2 \mathrm{H}), 7.50(\mathrm{br}, 2 \mathrm{H}), 7.32(\mathrm{br}, 4 \mathrm{H}) 6.91$ (br, $2 \mathrm{H})$, 3.79 (br, 2H), 2.04 (br, 1H), 1.8 (br, 6H), 1.42-1.24 (br, 40H), 0.870.84 (br, 6H).

Poly(N-(2-decyltetradecyl)-3,7-phenothiazine-S,S-dioxidealt-5,5-(4', $7^{\prime}$-di-2-thienyl-2' $1^{\prime}, 3^{\prime}$-benzothiadiazole)) (PPTDTBT-SS). In a Schlenk flask, monomer $8(0.214 \mathrm{~g}, 0.266 \mathrm{mmol})$ and 4,7-bis(5-bromothiophenyl)-2,1,3-benzothiadiazole (0.12 g, 0.266 mmol) was dissolved in toluene $(7 \mathrm{~mL})$, to this a solution of $\mathrm{K}_{3} \mathrm{PO}_{4}$ (286 mg, $1.34 \mathrm{mmol})$, trio-tolylphosphine $(10 \mathrm{mg}, 0.03 \mathrm{mmol})$ and deionized water $(1.5 \mathrm{~mL})$ was added. The mixture was vigorously stirred at room temperature under argon. After $30 \mathrm{~min}, \mathrm{Pd}_{2}(\mathrm{dba})_{3}(10$ $\mathrm{mg}, 0.011 \mathrm{mmol}$ ) was added to the reaction mixture and stirred at 90 ${ }^{\circ} \mathrm{C}$ for 3 days (end-capped with phenylboronic acid and bromobenzene). Finally, the solution was precipitated in a mixture of methanol and ammonia $(4: 1 \mathrm{v} / \mathrm{v}, 250 \mathrm{~mL})$. This was filtered off through $0.45 \mu \mathrm{m}$ nylon filter, washed on Soxhlet apparatus with methanol $(1 \mathrm{~d})$ and acetone $(1 \mathrm{~d})$. Then $0.14 \mathrm{~g}(61 \%)$ of the polymer was recovered as a deep-red powder $\left(M_{\mathrm{n}}=7.6 \times 10^{3} \mathrm{~g} / \mathrm{mol}\right.$, PDI $=$ 1.21). ${ }^{1} \mathrm{H}$ NMR $\left(600 \mathrm{MHz}, \mathrm{CDCl}_{3}\right): \delta(\mathrm{ppm}) 8.42(\mathrm{br}, 2 \mathrm{H}), 8.15(\mathrm{br}$, $2 \mathrm{H}), 7.93(\mathrm{br}, 4 \mathrm{H}), 7.50-7.40(\mathrm{br}, 4 \mathrm{H}) 4.16(\mathrm{br}, 2 \mathrm{H}), 2.07(\mathrm{br}, 1 \mathrm{H})$, $1.27-1.23(\mathrm{br}, 40 \mathrm{H}), 0.90-0.85(\mathrm{br}, 6 \mathrm{H})$.

\section{ASSOCIATED CONTENT}

\section{S Supporting Information}

DFT-optimized geometries and charge-density isosurfaces for the HOMO and LUMO levels of (a) (PTDTBT) $)_{1}$ and (b) (PTDTBT-SS $)_{1}$ model, ${ }^{1} \mathrm{H}$ NMR spectra of polymers, polymers:PCBM blend transistors, solar cell performance of polymer: $\mathrm{PC}_{61} \mathrm{BM}$, and GPC data. This material is available free of charge via the Internet at http://pubs.acs.org.

\section{AUTHOR INFORMATION}

\section{Corresponding Author}

*E-mail: yang@unist.ac.kr. Telephone: +82-52-217-2920. Fax: +82-52-217-2909.

\section{Notes}

The authors declare no competing financial interest.

\section{ACKNOWLEDGMENTS}

This work was supported by Basic Science Research Program through the National Research Foundation of Korea (NRF) funded by the Ministry of Education, Science and Technology (2010-0002494) and the National Research Foundation of Korea Grant funded by the Korean Government (MEST) (2010-0019408), (2010-0026163), (2010-0026916), and (NRF-2009-C1AAA001-0093020).

\section{REFERENCES}

(1) Cheng, Y. J.; Yang, S. H.; Hsu, C. S. Chem. Rev. 2009, 109, 5868.

(2) Gunes, S.; Neugebauer, H.; Sariciftci, N. S. Chem. Rev. 2007, 107, 1324.

(3) Yu, G.; Gao, J.; Hummelen, J. C.; Wudl, F.; Heeger, A. J. Science 1995, 270, 1789.

(4) Kim, G.; Yun, M. H.; Anant, P.; Cho, S.; Jacob, J.; Kim, J. Y.; Yang, C. Chem.-Eur. J. 2011, 17, 14681.

(5) Cheedarala, R. K.; Kim, G. H.; Cho, S.; Lee, J.; Kim, J.; Song, H. K.; Kim, J. Y.; Yang, C. J. Mater. Chem. 2011, 21, 843.

(6) Wang, E. G.; Ma, Z. F.; Zhang, Z.; Vandewal, K.; Henriksson, P.; Inganas, O.; Zhang, F. L.; Andersson, M. R. J. Am. Chem. Soc. 2011, 133, 14244.

(7) Price, S. C.; Stuart, A. C.; Yang, L. Q.; Zhou, H. X.; You, W. J. Am. Chem. Soc. 2011, 133, 4625.

(8) Huo, L. J.; Zhang, S. Q.; Guo, X.; Xu, F.; Li, Y. F.; Hou, J. H. Angew. Chem., Int. Ed. 2011, 50, 9697.

(9) Piliego, C.; Holcombe, T. W.; Douglas, J. D.; Woo, C. H.; Beaujuge, P. M.; Fréchet, J. M. J. J. Am. Chem. Soc. 2010, 132, 7595.

(10) Chen, H. Y.; Hou, J. H.; Zhang, S. Q.; Liang, Y. Y.; Yang, G. W.; Yang, Y.; Yu, L. P.; Wu, Y.; Li, G. Nat. Photonics 2009, 3, 649.

(11) Zhao, G. J.; He, Y. J.; Li, Y. F. Adv. Mater. 2010, 22, 4355.

(12) Cheng, Y. J.; Hsieh, C. H.; He, Y. J.; Hsu, C. S.; Li, Y. F. J. Am. Chem. Soc. 2010, 132, 17381.

(13) He, Z.; Zhong, C.; Huang, X.; Wong, W.-Y.; Wu, H.; Chen, L.; Su, S.; Car, Y. Adv. Mater. 2011, 23, 4636.

(14) Jørgensen, M.; Norrman, K.; Krebs, F. C. Sol. Energy Mater. Sol. Cells. 2008, 92, 686.

(15) Sun, Y. M.; Seo, J. H.; Takacs, C. J.; Seifter, J.; Heeger, A. J. Adv. Mater. 2011, 23, 1679.

(16) Hau, S. K.; Yip, H.-L.; Leong, K.; Jen, A. K.-Y. Org. Electron. 2009, 10, 719 .

(17) Park, S. H.; Roy, A.; Beaupre, S.; Cho, S.; Coates, N.; Moon, J. S.; Moses, D.; Leclerc, M.; Lee, K.; Heeger, A. J. Nat. Photonics 2009, 3, 297.

(18) Blouin, N.; Michaud, A.; Gendron, D.; Wakim, S.; Blair, E.; Neagu-Plesu, R.; Belletete, M.; Durocher, G.; Tao, Y.; Leclerc, M. J. Am. Chem. Soc. 2008, 130, 732.

(19) Svensson, M.; Zhang, F. L.; Veenstra, S. C.; Verhees, W. J. H.; Hummelen, J. C.; Kroon, J. M.; Inganäs, O.; Andersson, M. R. Adv. Mater. 2003, 15, 988.

(20) Cho, S.; Seo, J. H.; Park, S. H.; Beaupre, S.; Leclerc, M.; Heeger, A. J. Adv. Mater. 2010, 22, 1253.

(21) Cadogan, J. I. G.; Cameron-Wood, M.; Mackie, R. K.; Searle, R. J. G. J. Chem. Soc. 1965, 4831.

(22) Padhy, H.; Huang, J. H.; Sahu, D.; Patra, D.; Kekuda, D.; Chu, C. W.; Lin, H. C. J. Polym. Sci, Part A: Polym. Chem. 2010, 48, 4823. (23) Sang, G. Y.; Zou, Y. P.; Li, Y. F. J. Phys. Chem. C 2008, 112, 12058.

(24) Liu, Y.; Cao, H.; Li, J.; Chen, Z.; Cao, S.; Xiao, L.; Xu, S.; Gong, Q. J. Polym. Sci., Part A: Polym. Chem. 2007, 45, 4867.

(25) Cho, N. S.; Park, J. H.; Lee, S. K.; Lee, J.; Shim, H. K.; Park, M. J.; Hwang, D. H.; Jung, B. J. Macromolecules 2006, 39, 177.

(26) Kong, X. X.; Kulkarni, A. P.; Jenekhe, S. A. Macromolecules 2003, 36, 8992.

(27) Liu, B.; Najari, A.; Pan, C. Y.; Leclerc, M.; Xiao, D. Q.; Zou, Y. P. Macromol. Rapid Commun. 2010, 31, 391. 
(28) Kamtekar, K. T.; Dahms, K.; Batsanov, A. S.; Jankus, V.; Vaughan, H. L.; Monkman, A. P.; Bryce, M. R. J. Polym. Sci., Part A: Polym. Chem. 2011, 49, 1129.

(29) Scharber, M. C.; Wühlbacher, D.; Koppe, M.; Denk, P.; Waldauf, C.; Heeger, A. J.; Brabec, C. L. Adv. Mater. 2006, 18, 789.

(30) Brabec, C. J.; Cravino, A.; Meissner, D.; Sariciftci, N. S.; Fromherz, T.; Rispens, M. T.; Sanchez, L.; Hummelen, J. C. Adv. Funct. Mater. 2001, 11, 374.

(31) Kang, S.-M.; Leblebici, Y. CMOS Digital Integrated Circuits: Analysis and Design; McGraw-Hill: New York, 1996.

(32) Chen, L. M.; Hong, Z. R.; Li, G.; Yang, Y. Adv. Mater. 2009, 21, 1434.

(33) Sun, Y. M.; Takacs, C. J.; Cowan, S. R.; Seo, J. H.; Gong, X.; Roy, A.; Heeger, A. J. Adv. Mater. 2011, 23, 2226.

(34) Ma, H.; Yip, H.-L.; Huang, F.; Jen, A. K.-Y. Adv. Funct. Mater. 2010, 20, 1371.

(35) Zhang, Y.; Hau, S. K.; Yip, H.-L.; Sun, Y.; Acton, O.; Jen, A. K.Y. Chem. Mater. 2010, 22, 2696.

(36) Hsieh, C.-H.; Cheng, Y.-J.; Li, P.-J.; Chen, C.-H.; Dubosc, M.; Liang, R.-M.; Hsu, C.-S. J. Am. Chem. Soc. 2010, 132, 4887.

(37) Waldauf, C.; Morana, M.; Denk, P.; Schilinsky, P.; Coakley, K.; Choulis, S. A.; Brabec, C. J. Appl. Phys. Lett. 2006, 89, 233517.

(38) van Duren, J. K. J.; Yang, X. N.; Loos, J.; Bulle-Lieuwma, C. W. T.; Sieval, A. B.; Hummelen, J. C.; Janssen, R. A. J. Adv. Funct. Mater. 2004, 14, 425.

(39) Wienk, M. M.; Kroon, J. M.; Verhees, W. J. H.; Knol, J.; Hummelen, J. C.; van Hal, P. A.; Janssen, R. A. J. Angew. Chem., Int. Ed. 2003, 42, 3371.

\section{NOTE ADDED AFTER ASAP PUBLICATION}

This article posted ASAP on February 3, 2012. Scheme 1 has been revised. The correct version posted on February 7, 2012. 